\title{
Assessing the effect of meteorological factors on daily children's respiratory disease hospitalizations: a retrospective study
}

\section{Wenfang Guo}

Inner Mongolia Autonomous Region Academy of Traditional Medicine

\section{Letai Yi}

Inner Mongolia Autonomous Region Academy of Traditional Medicine

\section{Peng Wang}

The First Affiliated Hospital of Baotou Medical College

\section{Baojun Wang}

Inner Mongolia Baotou City Central Hospital

Minhui Li ( $\nabla$ prof_liminhui@yeah.net )

Inner Mongolia Autonomous Region Academy of Traditional Medicine https://orcid.org/0000-0002-5366-8464

\section{Research}

Keywords: Temperature, Humidity, Wind speed, Net effective temperature, Respiratory disease

Posted Date: April 7th, 2020

DOI: https://doi.org/10.21203/rs.3.rs-20210/v1

License: (9) (1) This work is licensed under a Creative Commons Attribution 4.0 International License. Read Full License 


\section{Abstract}

\section{Background}

Some previous studies have examined the effects of temperature, humidity, wind speed and atmospheric pressure on children morbidity, but few studies have evaluated health effects of combined effect of various meteorological factors. The purpose of this study was to assess the effect of daily changes in meteorological factors and their comprehensive effects on children's respiratory disease hospitalizations for different ages, genders and subtypes in Baotou, China.

\section{Methods}

Generalized additive models and distributed lag non-linear models were constructed to simultaneously assess the exposure-response associations between daily admission counts of children with respiratory diseases and daily net effective temperature and other meteorological factors as well as their lag dependencies.

Results

In general, the cumulative meteorological factors had greater effects on lower respiratory tract infections than upper respiratory tract infections (RR: temperature [4.2 vs. 2.7]; wind speed [3.1 vs. 2.5]; humidity [1.8 vs. 1.3]). The effects on children over 3 years old were greater than those on children aged 0-3 years (OR: temperature [4.4 vs. 1.3]; wind speed [4.4 vs. 1.5]), while the effects on female children were greater than those on male children (OR: temperature [2.6 vs. 1.8]; wind speed [3.3 vs. 1.6]). However, some differences were observed between groups with regard to the effect of humidity. Hence, the net effective temperature was calculated using comprehensive meteorological factors, and the influence range value and peak value of each group were determined.

Conclusions

The influence of meteorological factors on children's respiratory disease hospitalizations shows different characteristics in different subgroups. Hence, the net effective temperature was calculated using the comprehensive meteorological factors, and the influence range and peak value of each group were determined so as to recommend the corresponding measures accordingly.

\section{Background}

Respiratory disease is one of the most common diseases in children, which is affected by complex meteorological factors. Previous studies have revealed the relationship between children's respiratory diseases and meteorological factors, including temperature, humidity, wind speed and atmospheric pressure [1-3]. The results and conclusions are relatively unstable. Some studies suggest that the effects of cold spells on human health might be mainly due to the effects of daily temperature fluctuations as well as the impact of persistent and extreme climate change $[4,5]$. Temperature changes increase the rates of medical service utilization in terms of emergency department visits [6] and hospital admissions [7]. A meta-analysis in a previous work showed that the effects of comprehensive evaluations of temperature, humidity, and wind speed on disease incidence were better than that of a single evaluation of temperature [4]. This is an expected discovery because high winds could aggravate the physiological effects of cold temperatures, and a dry environment can stimulate additional 
external dust and other substances, thus affecting the respiratory system negatively. Due to the complicated patterns of the association of health outcomes with seasonal characteristics, several studies have evaluated the health effects of different air characteristics while integrating climatic conditions in the analysis [8]. The net effective temperature (NET) integrates temperature, relative humidity, and wind speed as a cooling indicator, and the NET is known to increase with rising temperature and relative humidity, and decrease with strong winds [9]. Respiratory diseases are related to a variety of outdoor environments. Notably, respiratory disease symptoms in children are aggravated by frequent changes in meteorological conditions [10]. Children are particularly vulnerable to environmental hazards because of their less developed immune systems compared to adults, but limited studies have examined the relationship between climate and morbidity among children [2]. Children have fewer and immature bronchial smooth muscles, a low proportion of anti-fatigue diaphragm fiber, and immature immune systems [11]. Thus, respiratory diseases occur more frequently in children.

Baotou City, China, has a temperate continental climate and relatively distinct seasonal characteristics with temperature variations. Climate change will also significantly increase the incidence of respiratory diseases such as seasonal flu, asthma, and pneumonia by affecting viral activity and transmission, changing the immune responses of the vectors and hosts, and facilitating the distribution of allergens $[3,12,13]$.

The purpose of this study was to explore the relationship between the daily changes in average temperature, average humidity, atmospheric pressure, wind speed, and hospitalization in patients of different ages and genders with respiratory diseases in the Baotou area. Moreover, their comprehensive effects on children's hospitalization for different patient groups were determined. This is the first comprehensive study to evaluate and compare the impacts of meteorological factors on the risk of children's respiratory disease hospitalization in China.

\section{Methods}

\section{Data source}

This study was conducted in Baotou, which is located in the central part of Inner Mongolia in China. Data on children's respiratory disease hospitalizations (RDHs) in this study were sourced from three major hospitals in Baotou: The First Affiliated Hospital of Baotou Medical College, Inner Mongolia Baotou City Central Hospital, and Zhong Meng Hospital of Baotou City. Our target population was aged less than 18 years and hospitalized for a natural respiratory disease between January 1, 2014 and December 31, 2018. The hospitalization data comprised daily admissions due to respiratory diseases (according to ICD-10, J00-99, and excluding lung diseases due to external agents). We screened the admission registration information records. Then, we calculated the number of children's respiratory admission cases per day, which were divided into two levels: children aged $0-3$ years and those older than 3 years.

Meteorological data, namely daily mean temperature, relative humidity, wind speed and barometric pressure were obtained from the Baotou Meteorological Administration.

\section{Definition of the NET}

The NET is an index that integrates the effects of temperature, humidity, and wind speed to evaluate weather stress [9]. The formula for calculating the NET is as follows: 


$$
N E T=37-\frac{37-T}{0.68-0.0014 H+\left(1.76+1.4 V^{0.75}\right)^{-1}}-0.29 T(1-0.01 H)
$$

where $T$ is the ambient temperature $\left({ }^{\circ} \mathrm{C}\right), v$ refers to the wind speed $(\mathrm{m} / \mathrm{s})$, and $H$ is the relative humidity $(\%)$. A large positive NET value implies an exceptionally high heat load, while a large negative value represents large heat loss. In hot weather, the NET value increases with an increase in temperature and/or relative humidity, but it decreases with an increase in wind speed. In cold weather, the NET value decreases with an decrease in temperature, and with an increase in relative humidity, and wind speed [9].

\section{Statistical analysis}

Generalized additive models (GAM) and distributed lag non-linear models (DLNM) were constructed to simultaneously assess the exposure-response associations between daily admission counts of children with respiratory diseases and daily NET values and other meteorological factors as well as their lag dependencies. The models were formulated as follows:

$\log (E(Y))=\alpha+\beta($ Meteorological factors, $\operatorname{Lag}=14)+n s($ time,$d f=4 /$ year $)+\eta$ Holiday $+\delta$ Dow $t$

where $E(Y)$ is the expected number of daily hospital visits of children due to respiratory disease. The meteorological factors include daily mean temperature, humidity, pressure, wind speed, and NET. $\beta$ is the regression coefficient. $n s$ is the natural spline-smoothing function. Holiday denotes the number of public holidays, and Dow $t$ is the categorical day of the week. df equals $24,5,5,5,5$, and 3 for time, temperature, humidity, pressure, wind speed, and NET, respectively.

The Akaike information criterion (AIC) was used to select the model. All associations were reported as the relative risk (RR) with the corresponding 95\% confidence interval $(\mathrm{Cl})$ compared to the defined reference value. All the statistical analyses were conducted using R3.6.1.

\section{Results}

In total, 30,486 children's RDHs were recorded among children during the whole study period. Table 1 shows the summary statistics for mean temperature, relative humidity, daily barometric pressure, and wind speed, and cause-, age-, and gender-specific pediatric children's RDHs. The average mean temperature was $8.3^{\circ} \mathrm{C}$ (range: -19.7-30), and the average relative humidity was $54.8 \%$ (11.5-97.0\%). The average barometric pressure was 902.2 Pa (885-924.7 Pa). The average wind speed was $2.9 \mathrm{~m} / \mathrm{s}(0.9-7.8 \mathrm{~m} / \mathrm{s})$, respectively. The daily number of children's RDHs was higher among children aged 0-3 years (median: 10) than among those older than 3 years (median: 7). The daily number of RDHs was greater among male children (median: 9) than female children (mean: 7). The daily number of children's RDHs was greater among patients with lower respiratory tract infections (median: 12) than those with upper respiratory tract infections (median: 5) 
Table 1

Descriptive summary for children hospitalizations of respiratory disease and meteorological factors in Baotou (2014 - 2018) .

\begin{tabular}{|lllllll|}
\hline & Min. & $\mathrm{P}(1$ th) & Median & Mean & P(99th) & Max. \\
\hline Total respiratory $(\mathrm{n}=30486)$ & 1 & 3 & 16 & 17 & 39 & 70 \\
\hline Lower respiratory infection $(\mathrm{n}=22792)$ & 0 & 1 & 12 & 12 & 33 & 67 \\
\hline Upper respiratory infection $(\mathrm{n}=7043)$ & 0 & 0 & 5 & 5 & 15 & 34 \\
\hline 0-3-years-old group $(\mathrm{n}=18041)$ & 0 & 1 & 9 & 10 & 25 & 49 \\
\hline$>$ 3 years old group $(\mathrm{n}=12445)$ & 0 & 0 & 6 & 7 & 21 & 27 \\
\hline male $(\mathrm{n}=16772)$ & 0 & 1 & 9 & 9 & 22 & 62 \\
\hline female $(\mathrm{n}=13714)$ & 0 & 1 & 7 & 7 & 19 & 42 \\
\hline Meteorological variables & & & & & & 30 \\
\hline Mean temperature $\left({ }^{\circ} \mathrm{C}\right)$ & -19.7 & -15.6 & 10.1 & 8.3 & 27.3 & 30 \\
\hline Relative humidity $(\%)$ & 11.5 & 21 & 55.3 & 54.8 & 90.5 & 97 \\
\hline Pressure $(\mathrm{PA})$ & 885 & 889.6 & 902.2 & 902.2 & 917.2 & 924.7 \\
\hline Wind speed $(\mathrm{m} / \mathrm{s})$ & 0.9 & 1.1 & 2.7 & 2.9 & 6.9 & 7.8 \\
\hline NET & -34.5 & -26.2 & 3.0 & 0.8 & 21.6 & 24 \\
\hline
\end{tabular}

Figure 1 and Table 2 shows the cumulative effects (lag days: $0-14$ ) of the different meteorological factors on the children's RDHs stratified by age, gender, and subtype. The RR value and 95\% Cls of the effects of different indicators on the children's RDHs on the current day and lag days 1 through 14 can be found in Table S1-S3 (Supplemental materials). Figure 2 shows the significant lag effects of temperature, humidity, wind speed and pressure on lag days 0 through 14 . The relationship between temperature and children's respiratory disease hospitalizations was inverted U-shaped. The cumulative effects of daily average temperature on the children's $\mathrm{RDH}$ increased as the temperature changed from cold to hot and decreased as it changed from hot to cold. Total RDHs, female children, and children with upper respiratory tract infections were more susceptible to temperatures from $0-20^{\circ} \mathrm{C}$, whereas children with lower respiratory tract infections and those older than 3 years were more susceptible to temperatures from $-10-20^{\circ} \mathrm{C}$. male children were more susceptible to temperatures from $9-18^{\circ} \mathrm{C}$. Temperature variations did not exert much effect on hospital visits for children aged 0-3 years. For lag effects of days 0 through 14 , the largest single-day RRs of daily average temperature (temperature [ $8^{\circ} \mathrm{C}$ ] for the highest hospitalization risk relative to the lowest cause-specific hospitalization temperature $\left.\left[30^{\circ} \mathrm{C}\right]\right)$ on hospitalization for total RDHs, lower respiratory tract infections, upper respiratory tract infections, 0-3-year-old patients, patients older than 3 years, male, and female children were 1.12 (95\% Cl: 1.05-1.19) on lag day 10, 1.63 (95\% Cl: $1.03-2.60)$ on the current day, 1.18 (95\% Cl: $1.06-1.29)$ on lag day 9, 1.12 (95\% Cl: 1.01-1.25) on lag day $8,1.21$ (95\% Cl: $1.03-1.43)$ on lag day $12,1.16$ (95\% Cl: $1.01-1.32)$ on lag day 13 , and 1.19 (95\% Cl: $1.05-1.35$ ) on lag day 8 , respectively. 
Table 2

Cumulative relative risk of meteorological factors in different respiratory subgroups.

\begin{tabular}{|c|c|c|c|c|c|c|c|}
\hline \multirow[t]{2}{*}{ Indicators } & \multicolumn{7}{|c|}{ Cumulative $\mathrm{RR}(95 \mathrm{Cl})$ in respiratory subgroups } \\
\hline & $\begin{array}{l}\text { Total } \\
\text { respiratory }\end{array}$ & $\begin{array}{l}\text { Lower } \\
\text { respiratory } \\
\text { infection }\end{array}$ & $\begin{array}{l}\text { Upper } \\
\text { respiratory } \\
\text { infection }\end{array}$ & $\begin{array}{l}0- \\
3 \text { years }\end{array}$ & $\begin{array}{l}> \\
3 \text { years }\end{array}$ & male & female \\
\hline $\begin{array}{l}\text { Temperature }(8 \\
\left.\text { vs } 30^{\circ} \mathrm{C}\right)\end{array}$ & $\begin{array}{l}2.2(1.3- \\
3.5)\end{array}$ & $\begin{array}{l}4.2(1.9- \\
9.6)\end{array}$ & $\begin{array}{l}2.7(1.4- \\
4.9)\end{array}$ & $\begin{array}{l}1.3(0.9- \\
1.9)\end{array}$ & $\begin{array}{l}4.4(2.1- \\
8.9)\end{array}$ & $\begin{array}{l}1.8(1.0- \\
3.3)\end{array}$ & $\begin{array}{l}2.6(1.3- \\
5.2)\end{array}$ \\
\hline $\begin{array}{l}\text { Humidity (21 } \\
\text { vs } 80.1 \%)\end{array}$ & $\begin{array}{l}1.7(1.3- \\
2.2)\end{array}$ & $\begin{array}{l}1.8(1.3- \\
2.4)\end{array}$ & $\begin{array}{l}1.3(0.8- \\
2.1)\end{array}$ & $\begin{array}{l}2.2(1.6- \\
2.9)\end{array}$ & $\begin{array}{l}1.2(0.8- \\
1.9)\end{array}$ & $\begin{array}{l}1.7(1.2- \\
2.3)\end{array}$ & $\begin{array}{l}1.6(1.1- \\
2.3)\end{array}$ \\
\hline $\begin{array}{l}\text { Wind } \\
\text { speed(6.9 vs } \\
0.9 \mathrm{~m} / \mathrm{s})\end{array}$ & $\begin{array}{l}2.4(1.3- \\
4.4)\end{array}$ & $\begin{array}{l}3.1(1.4- \\
6.8)\end{array}$ & $\begin{array}{l}2.5(0.8- \\
8.1)\end{array}$ & $\begin{array}{l}1.5(0.7- \\
2.9)\end{array}$ & $\begin{array}{l}4.4(1.6- \\
12.4)\end{array}$ & $\begin{array}{l}1.6(0.7- \\
3.3)\end{array}$ & $\begin{array}{l}3.3(1.4- \\
7.7)\end{array}$ \\
\hline $\begin{array}{l}\text { Pressure }(917.2 \\
\text { vs } 885 \mathrm{~Pa})\end{array}$ & $\begin{array}{l}0.5(0.2- \\
1.7)\end{array}$ & $\begin{array}{l}0.6(0.1- \\
2.8)\end{array}$ & $\begin{array}{l}0.8(0.7- \\
1.0)\end{array}$ & $\begin{array}{l}0.7(0.2- \\
2.7)\end{array}$ & $\begin{array}{l}0.3(0.1- \\
2.1)\end{array}$ & $\begin{array}{l}0.3(0.1- \\
1.2)\end{array}$ & $\begin{array}{l}1.07(0.2- \\
5.7)\end{array}$ \\
\hline $\begin{array}{l}\text { NET (peaks vs } \\
24 \text { ) }\end{array}$ & $\begin{array}{l}1.8(1.4- \\
2.4)^{a}\end{array}$ & $\begin{array}{l}3.7(2.1- \\
6.6)^{b}\end{array}$ & $\begin{array}{l}2.0(1.4- \\
2.8)^{c}\end{array}$ & $\begin{array}{l}1.3(0.95- \\
1.8)^{d}\end{array}$ & $\begin{array}{l}2.9(1.8- \\
4.7)^{e}\end{array}$ & $\begin{array}{l}1.78(1.3- \\
2.4)^{f}\end{array}$ & $\begin{array}{l}1.9(1.3- \\
2.7)^{\mathrm{g}}\end{array}$ \\
\hline
\end{tabular}

The cumulative effect of daily humidity on children's RDHs increased with decreasing daily humidity (the 1 th percentile of humidity [21\%] relative to the lowest cause-specific RDHs humidity [80.1\%]), especially for lower respiratory tract infections (RR: $1.8,95 \% \mathrm{Cl}$ : 1.3-2.4), patients aged $0-3$ years (RR: $2.2,95 \% \mathrm{Cl}: 1.6-2.9$ ), and male children (RR: 1.7, 95\% Cl: 1.2-2.3). The lowest daily humidity showed no significant effect on patients older than 3 years. For lag effects of days 0 through 14, the largest single-day RRs on total children's RDHs, lower respiratory tract infections, upper respiratory tract infections, 0-3-year-old children, children older than 3 years, male, and female children were 1.09 (95\% Cl: $1.00-1.19)$ on the current day, 1.13 (95\% $\mathrm{Cl}: 1.00-1.26)$ on the current day, 1.05 (95\% Cl: 0.99-1.11) on lag day 8, 1.13 (95\% Cl: 1.02-1.25) on the current day, 1.05 (95\% Cl: $0.92-1.22)$ on the current day, 1.06 (95\% Cl: 1.02-1.11) on lag day 7, and 1.10 (95\% Cl: $1.04-1.17)$ on lag day 1 , respectively.

The cumulative effect of wind speed on children's RDHs increased with increasing daily wind speed (the 99th wind speed [6.9 m/s] relative to the lowest cause-specific RDHs wind speed [0.9 m/s]), especially for lower respiratory tract infections (RR: 3.1, 95\% Cl:1.4-6.8), patients older than 3 years (RR: 4.4, 95\% Cl: 1.6-12.4), and female children (RR: 3.3, 95\% Cl: 1.4-7.7). For lag effects of days 0 through 14, the largest single-day RRs of wind speed on total children's RDHs, lower respiratory tract infections, upper respiratory tract infections, 0-3year-old patients, patients older than 3 years, male, and female children were 1.09 (95\% Cl: 1.01-1.17) on lag day 1, 1.12 (95\% Cl: 1.02-1.22) on lag day 1, 1.10 (95\% Cl: 0.98-1.23) on lag day 2, 1.05 (95\% Cl: 0.98-1.12) on lag day $2,1.14$ (95\% Cl: $1.01-1.29)$ on lag day 1, 1.07 (95\% Cl: $1.00-1.15)$ on lag day 2, and 1.09 (95\% Cl: $1.00-$ 1.18) on lag day 2 , respectively. 
The cumulative effect of daily barometric pressure on the children's RDHs decreased with an increase in the daily barometric pressure, but the result was not statistically significant. For lag effects of days 0 through 14 , the largest single-day RR of barometric pressure (the 99th percentile of barometric pressure [917.2 Pa] relative to the lowest cause-specific barometric pressure [885 Pa] for RDHs) on total children's RDHs was 0.89 (95\% Cl: $0.81-$ 0.99 ) on lag day 11. The largest cumulative RR for RDHs' for male children was 0.87 (95\% Cl: $0.78-0.99)$ on lag day 10.

The cumulative effect of the NET on total children's RDHs increased for NET values of -10-20, peaking at an NET value of 2.8 (RR: $1.8,95 \% \mathrm{Cl}: 1.4-2.4$ ). The cumulative effect of the NET on lower respiratory tract infections increased for NET values of -20.2-24, peaking at an NET value of -5.3 (RR: 3.7, 95\% Cl: 2.1-6.6). The cumulative effect of the NET on upper respiratory tract infections increased for NET values of -8.2-18.8, peaking at an NET value of 3.6 (RR: $1.8,95 \%$ Cl: 1.4-2.4). The cumulative effect of the NET on RDHs of patients older than 3 years increased for NET values of -13.8-24, peaking at an NET value of -2.4 (RR: $2.9,95 \%$ Cl: $1.8-4.7$ ). The cumulative effect of the NET on male children RDHs increased with NET values of $-6.2-24$, peaking when the NET was 6 (RR: 1.8, 95\% Cl: 1.3-2.4). The cumulative effect of the NET on female children RDHs increased with NET values from - 8.1-11.9, and peaked when the NET value was 2.1 (RR: 1.87, 95\% Cl: 1.3-27) (Fig. 3). For the effects of lag days 0 through 14, the largest single-day RRs of the daily NET (the peak of RDHs relative to the lowest cause-specified RDHs [24]) on total RDHs, lower respiratory tract infections, upper respiratory tract infections, 0-3-year-old patients, patients older than 3 years, male and female children were 1.13 (95\% Cl: 1.061.19), 1.16 (95\% Cl: $1.09-1.25)$ on lag day $8,1.09$ (95\% Cl: $1.01-1.17)$ on lag day $10,1.12$ (95\% Cl: $1.04-1.20)$ on lag day $8,1.14$ (95\% Cl: $1.06-1.23)$ on lag day $9,1.12(95 \% \mathrm{Cl}: 1.05-1.18)$ on lag day 9 , and $1.14(95 \% \mathrm{Cl}$ : $1.05-1.23$ ) on lag day 8 , respectively (Table $\mathbf{S 4}$ ).

\section{Discussion}

The meteorological factors were significantly associated with the children's RDHs, but the effects of each factor were different for various ages, genders, and respiratory infection subtypes. The relationship between temperature and children's respiratory disease hospitalizations was inverted U-shaped. The extreme cold and hot temperatures had no effects on the children's hospitalization for respiratory diseases. The impact of temperature on children's RDHs was realized when the temperature changed from cold to hot or vice versa. This kind of temperature change mainly occurs in spring and autumn in Baotou. Humidity showed negative effects on RDHS but no association was evident for the RDHs of 0-3-year-old patients. Wind speed showed positive associations with total RDHs, patients older than 3 years, male and female children. Barometric pressure showed no associations with the RDHs. In general, the cumulative meteorological factors showed greater effects on lower respiratory tract infections than upper respiratory tract infections; the effects on patients over 3 years old were greater than those for 0-3-year-olds; the effects on female children were greater than those on male children. However, some differences were observed between groups with regard to the effect of humidity. Hence, the NET value was calculated using comprehensive meteorological factors, and the influence range value and peak value of each group were determined.

As per the current research findings, most studies point to the impacts of extremely cold and hot environments on respiratory diseases $[1,3,14-20]$. A time series analysis of asthma cases in Shenyang showed that children's asthma risk increases with a decrease in temperature [3]. A study of the effects of temperature on respiratory diseases in Lanzhou, China, showed that the peak period of respiratory diseases ranged from November to 
March of the next year. Both low and high temperatures increase the risk of hospitalization for respiratory disease [18]. Moreover, the risk of children suffering from respiratory diseases in other environments has been reported. A study in Beijing showed that the incidence of respiratory diseases in children infected with adenovirus was positively correlated with the average monthly temperature and negatively correlated with the wind speed. [12]. A study in Seoul, Korea, found that the impact of the dry season on children's respiratory health was strongest in spring for those aged 0-4 years, while the impact of the moist season on children's respiratory health was strongest for ages 5-9 years [11]. In terms of temperature, the utilization rate of medical services for respiratory diseases in 5-9-year-old children increased significantly in moderate temperature environments [11]. Another study employing stratified analysis by season in Seoul found that the strongest effect on allergic rhinitis occurred in autumn (September-November) [13].

According to the results of a comparative study of the current literature, many works have focused on children's respiratory diseases in extremely cold and hot environments, while some of these support our findings: children are more susceptible to respiratory diseases in relatively mild environment than in extremely cold and hot environments. The following have been proposed as the possible reasons for this finding. The biological mechanism of the relationship between relatively mild environments and children's respiratory diseases may be related to the effect of allergen (e.g., mites and pollen) growth. The Asian dust storm was also associated with hospital admissions for respiratory diseases [21,22]. These meteorological factors usually appear in spring and autumn in Baotou. Compared with winter, the temperature is warmer, the humidity is lower, and the wind speed is higher. Another reason for this finding was that lower respiratory tract infections can be caused by several pathogens, but respiratory viruses are the most common cause for lower respiratory tract infections in children. Geographical and meteorological factors significantly affect the etiology of respiratory virus infections, which is reflected in the regional and seasonal changes of respiratory virus circulation. For instance, the respiratory syncytial virus exhibits notable seasonal distributions, namely beginning in early autumn, peaking at the end of November or in early December, and gradually decreasing in spring. Moreover, no delay was observed between respiratory syncytial virus detection in communities and hospitals. However, adenovirus, influenza, and human parainfluenza virus were more frequently detected in the spring and summer months, between March and August $[23,24]$. A study on admission of children with respiratory diseases in Beijing showed that the most common diagnosis $(86.11 \%)$ in the adenovirus-positive cases was pneumonia, which was accompanied by the common signs and symptoms of fever and cough [12]. In addition, differences among populations as well as varying local climates, socio-economic conditions, demographic factors, and degrees of adaptation to the local environment were also factors that adjust the relationship between meteorological factors and respiratory diseases.

Our results showed that the influence of meteorological factors on lower respiratory tract diseases was greater than that on upper respiratory tract diseases. Respiratory diseases could be acute or chronic. The former type is responsible for the majority of the hospitalization cases in children. Acute respiratory infections caused by viruses or bacteria can affect either the lower respiratory tract (below the vocal cords) or the upper respiratory tract. The most common (upper respiratory tract) infections were colds, acute sinusitis, acute pharyngitis, and acute tonsillitis. Lower respiratory diseases included pneumonia, bronchopneumonia, acute bronchitis, and bronchiolitis, which were less common than the upper respiratory tract infections, but were usually more severe and had a higher incidence of hospitalization [25]. Another finding of our study was that the effect of meteorological factors on respiratory diseases in patients older than 3 years was greater than that on these 
diseases in patients aged 0-3 years. The effect of meteorological factors on respiratory diseases in female children was greater than that in male children. Children older than 3 years may play outdoors more often than younger children, which may increase their exposure to the external environment [2]. The development process of older female children differs considerably from that of male children; for example, the increase in estrogen may affect their thermoregulation functions, making female children more vulnerable to the influence of relatively low temperatures than male children [26].

To assess the delayed effect between exposure and health outcomes, we estimated the delayed effect for 14 days, including the day of hospitalization for respiratory tract diseases. Various delayed effects of respiratory diseases related to meteorological factors (temperature, humidity, and wind speed) have been confirmed in some studies to last from 2-3 days to several weeks $[3,11]$. In our study, the utilization of pediatric medical services due to respiratory diseases was considered as the research object, and it was found that children show a relatively immediate response compared with adults. In fact, while assessing the impact of meteorological changes on the health of respiratory tract diseases in children, it was observed that children's delayed impact occurred within a week or a little more than a week, a timeline that may be more sensitive to meteorological factors due to children's less developed immune systems, special physiques, and still-maturing respiratory systems [2].

Our study used the NET, which integrates temperature, relative humidity, and wind speed as a cooling indicator, to evaluate the impact of climate on hospitalization for children's respiratory diseases. Based on the NET values, the influence range and peak value of each group were determined. The results showed that the influence range for lower respiratory tract infections was extended to slightly cold ranges compared to the case for upper respiratory tract infections. Compared with male children, the sensitive peak for female children was colder, and those over the age of 3 years were more inclined to exhibit a colder sensitive peak value than those between 0 and 3 years. This comprehensive evaluation index could accurately evaluate the impact of meteorological factors on different groups of hospitalization for respiratory disease, and thus, it would be prudent to take different measures to protect children so as to reduce their exposure under sensitive meteorological conditions.

This study suffers from some limitations. First, this work can be described as an ecological study. It lacked data related to exposure for individuals and could not ascertain the impact of an individual's activity patterns.

Second, no outdoor air pollution data were used in our study. However, their inclusion can modify the association between other meteorological factors and the risk of hospital admissions. Additionally, our data only included severely affected patients at three large hospitals and excluded outpatients and emergency patients. Therefore, it was impossible to comprehensively summarize the impact of meteorological factors on children with mild and severe respiratory diseases.

\section{Conclusions}

The results of this comprehensive evaluation indicated that the relationship between temperature and children's RDHs was inverted U-shaped. Humidity showed negative effects and wind speed showed positive effects on children's RDHs. In general, the cumulative meteorological factors had the greater effects on lower respiratory tract infections than upper respiratory tract infections. The effects on children over 3 years of age were greater than those between 0 and 3 years of age. Moreover, the effects on female children were greater than those on male children. The NET value was calculated using important and relevant meteorological factors, and the 
influence range value and peak value of each group were determined to suggest the corresponding appropriate measures.

\section{Abbreviations}

NET: Net Effective Temperature; RDHs: Respiratory Disease Hospitalizations; GAM: Generalized Additive Models; DLNM: Distributed Lag Non-linear Models; AIC: Akaike Information Criterion; RR: Relative Risk; Cl: Confidence Interval.

\section{Declarations}

\section{Acknowledgments}

We appreciate the Baotou Meteorological Bureau providing meteorological data for our study.

\section{Authors' contributions}

WG was involved in study design, extracted data, analysis, and interpretation, manuscript drafting and review; LY was involved in study design, manuscript review; PW and BW were involved in extracted data and data analysis; $\mathrm{ML}$ was involved in study design, manuscript drafting and review.

\section{Funding}

No funding was received.

Ethics approval and consent to participate

Not applicable.

\section{Consent for publication}

Not applicable.

\section{Competing interests}

The authors declare that they have no competing interests.

\section{Availability of data and materials}

The datasets used and/or analysed during the current study are available from the corresponding author on reasonable request.

\section{Author details}

${ }^{1}$ Inner Mongolia Autonomous Region Academy of Traditional Medicine, Hohhot (010020), China. ${ }^{2}$ Inner Mongolia Hospital of traditional Chinese Medicine, Hohhot (010020), China. ${ }^{3}$ The First Affiliated Hospital of Baotou Medical College, Baotou (014000), China. ${ }^{4}$ Inner Mongolia Baotou City Central Hospital, Baotou (014040), China. ${ }^{5}$ Baotou Medical College, Baotou (014060), China. 


\section{References}

1. Chan EY, Goggins WB, Yue JS, Lee P. Hospital admissions as a function of temperature, other weather phenomena and pollution levels in an urban setting in China. Bull World Health Organ. 2013;91(8):576-84.

2. Xu Z, Hu W, Tong S. Temperature variability and childhood pneumonia: an ecological study. Environ Health. 2014;13(1):51.

3. Zhang H, Liu S, Chen Z, Zu B, Zhao Y. Effects of variations in meteorological factors on daily hospital visits for asthma: A time-series study. Environ Res. 2020;182:109115.

4. Song X, Wang S, Hu Y, Yue M, Zhang T, Liu Y, et al. Impact of ambient temperature on morbidity and mortality: An overview of reviews. Sci Total Environ. 2017;586:241-54.

5. Song X, Wang S, Li T, Tian J, Ding G, Wang J, et al. The impact of heat waves and cold spells on respiratory emergency department visits in Beijing. ChinaSci Total Environ. 2018;615:1499-505.

6. Kim J, Lim Y, Kim H. Outdoor temperature changes and emergency department visits for asthma in Seoul, Korea: a time-series study. Environ Res. 2014;135:15-20.

7. Lim YH, Hong YC, Kim H. Effects of diurnal temperature range on cardiovascular and respiratory hospital admissions in Korea. Sci Total Environ. 2012;417-418:55-60.

8. Lin YK, Wang YC, Lin PL, Li MH, Ho TJ. Relationships between cold-temperature indices and all causes and cardiopulmonary morbidity and mortality in a subtropical island. Sci Total Environ. 2013;461-462:627 - 35.

9. Li PW, Chan ST. Application of a weather stress index for alerting the public to stressful weather in Hong Kong. Meteorol Appl. 2000;7:369-75.

10. Hu Y, Xu Z, Jiang F, Li S, Liu S, Wu M, et al. Relative impact of meteorological factors and air pollutants on childhood allergic diseases in Shanghai, China. Sci Total Environ. 2020;1(706):135975.

11. Kim J, Lee JY. Synoptic approach to evaluate the effect of temperature on pediatric respiratory diseaserelated hospitalization in Seoul, Korea. Environ Res. 2019;178:108650.

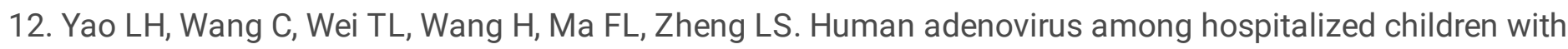
respiratory tract infections in Beijing, China, 2017-2018. Virol J. 2019;16(1):78.

13. Kim H, Kim H, Lee JT. Assessing the cold temperature effect on hospital visit by allergic rhinitis in Seoul, Korea. Sci Total Environ. 2018;633:938-45.

14. Xu Z, Hu W, Su H, Turner LR, Ye X, Wang J, et al. Extreme temperatures and paediatric emergency department admissions. J Epidemiol Community Health. 2014;68(4):304-11.

15. Xu Z, Huang C, Hu W, Turner LR, Su H, Tong S. Extreme temperatures and emergency department admissions. for childhood asthma in Brisbane, Australia. Occup Environ Med. 2013;70:730-5.

16. Xu Z, Etzel RA, Su H, Huang C, Guo Y, Tong S. Impact of ambient temperature on children's health: a systematic review. Environ Res. 2012;117:120-31.

17. Mourtzoukou EG, Falagas ME. Exposure to cold and respiratory tract infections. Int J Tuberc Lung Dis. 2007;11:938-43.

18. Chai G, He H, Su Y, Sha Y, Zong S. Lag effect of air temperature on the incidence of respiratory diseases in Lanzhou. Chinalnt J Biometeorol. 2020;64(1):83-93.

19. Iñiguez C, Schifano P, Asta F, Michelozzi P, Vicedo-Cabrera A, Ballester F. Temperature in summer and children's hospitalizations in two Mediterranean cities. Environ Res. 2016;150:236-44. 
20. Islam MS, Chaussalet TJ. Koizumi N.Towards a threshold climate for emergency lower respiratory hospital admissions. Environ Res. 2017;153:41-7.

21. Lin YK, Chen CF, Yeh HC, Wang YC. Emergency room visits associated with particulate concentration and Asian dust storms in metropolitan Taipei. J Expo Sci Environ Epidemiol. 2016;26(2):189-96.

22. Yang LF, Cai LM, Li M, Liu JT, Wang ZN, Wang WH, et al. A 10-year retrospective study of alterative aeroallergens sensitization spectrum in urban children with allergic rhinitis. Ther Clin Risk Manag. 2018;14:409-16.

23. Smithgall M, Maykowski P, Zachariah P, Oberhardt M, Vargas CY, Reed C, et al. Epidemiology, clinical features, and resource utilization associated with respiratory syncytial virus in the community and hospital. Influenza Other Respir Viruses. 2020. doi:.

24. Wen S, Yu M, Zheng G, Lv F, Chen X, Lin L, et al. Changes in the etiology of viral lower respiratory tract infections in hospitalized children in Wenzhou, China: 2008-2017. J Med Virol. 2019. doi:.

25. Green D, Bambrick H, Tait P, Goldie J, Schultz R, Webb L, et al. Differential Effects of Temperature Extremes on Hospital Admission Rates for Respiratory Disease between Indigenous and Non-Indigenous Australians in the Northern Territory. Int J Environ Res Public Health. 2015;12(12):15352-65.

26. Anderson CA, Zhu G, Falchi M, et al. A genome-wide linkage scan for age atmenarche in three. populations of European descent. J Clin Endocrinol Metab. 2008;93:3965-70.

\section{Figures}



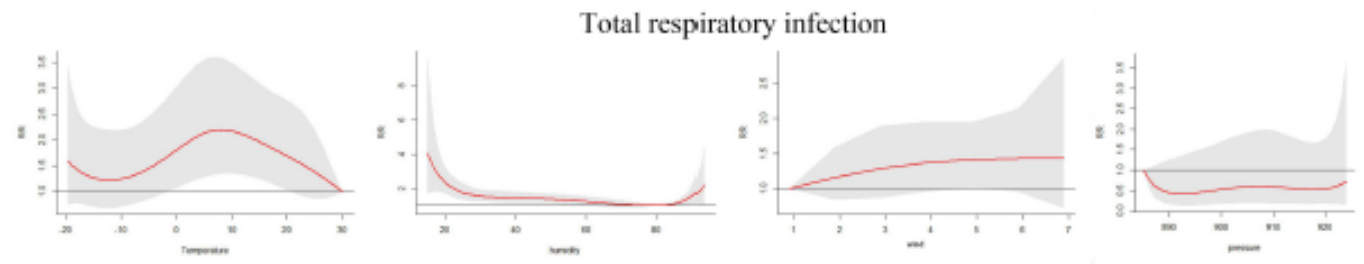

Lower respiratory
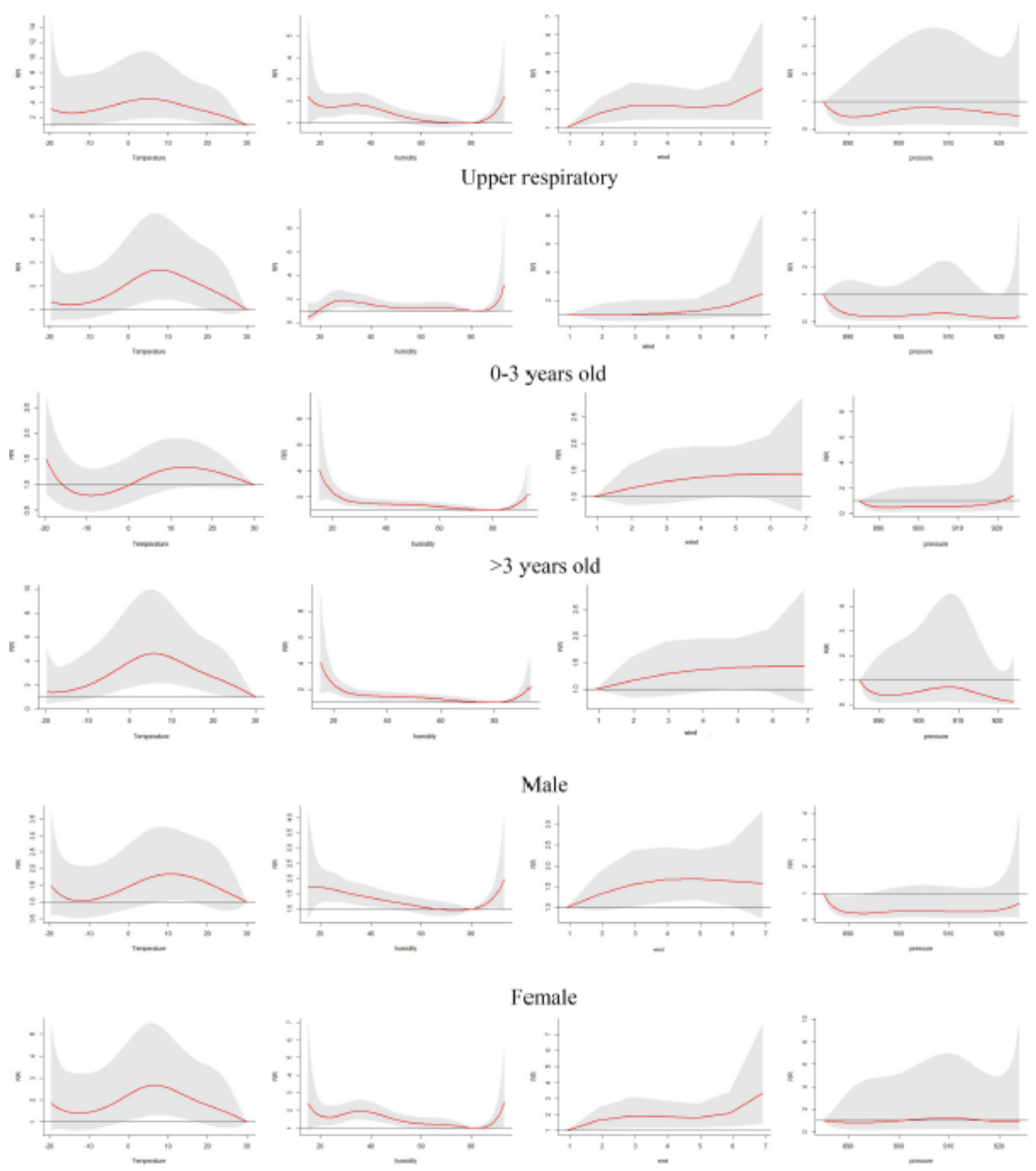

\section{Figure 1}

Cumulative effects of meteorological factors on respiratory hospitalization stratified by age, gender, and respiratory subtypes. 

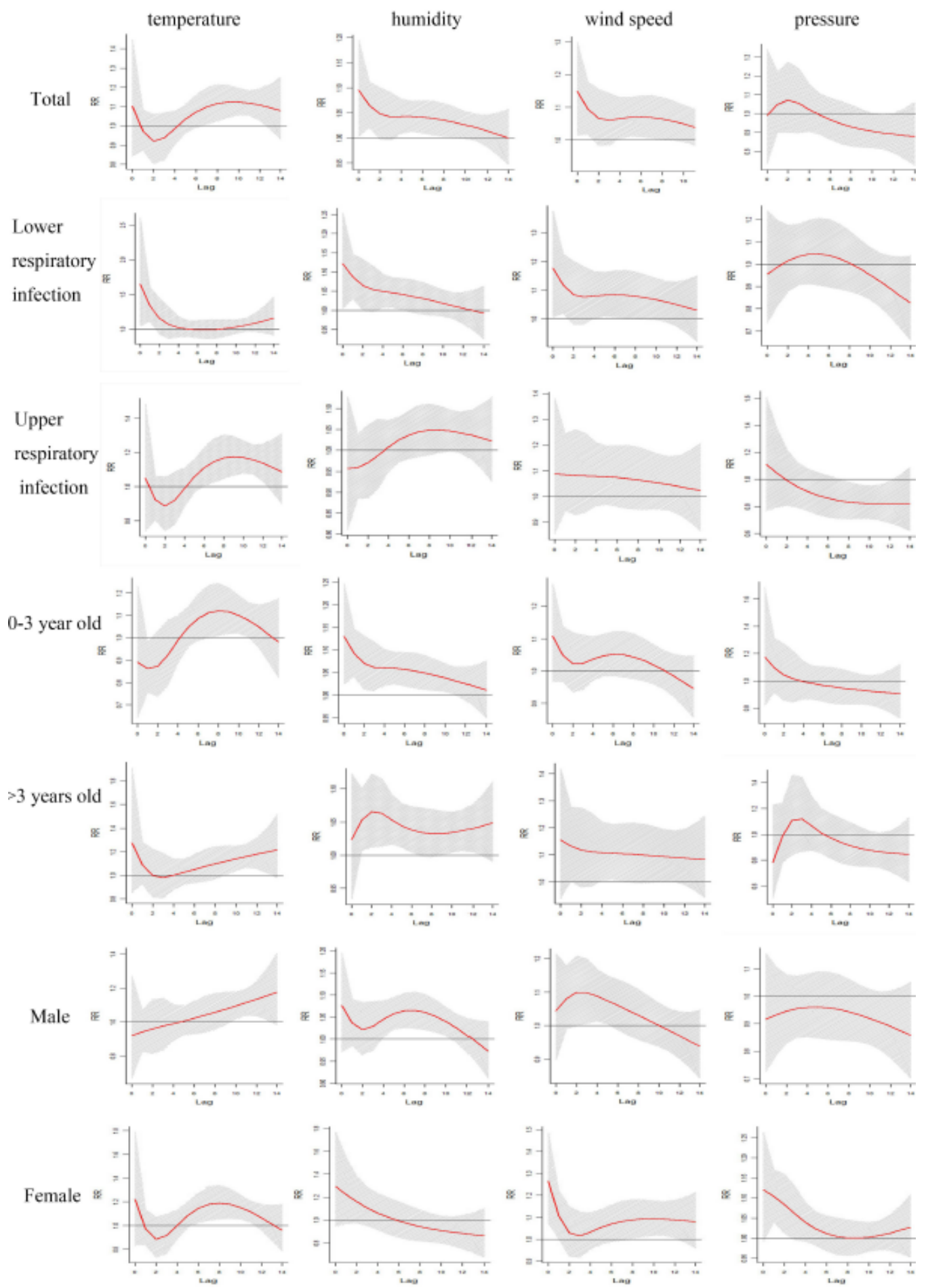

\section{Figure 2}

Variations in lag effects of daily average temperature, humidity, wind speed, and pressure on children's RDHs for lag days 0 through 14 (A: temperature $\left(8\right.$ vs. $30^{\circ}$ C); B: daily humidity (21 vs. $\left.80.1 \%\right)$; C: wind speed (6.9 vs. 0.9 $\mathrm{m} / \mathrm{s}$ ); D: daily barometric pressure (917 vs. $885 \mathrm{~Pa}$ ). 
Total respiratory infection Lower respiratory infection Upper respiratory infection 0-3 years old
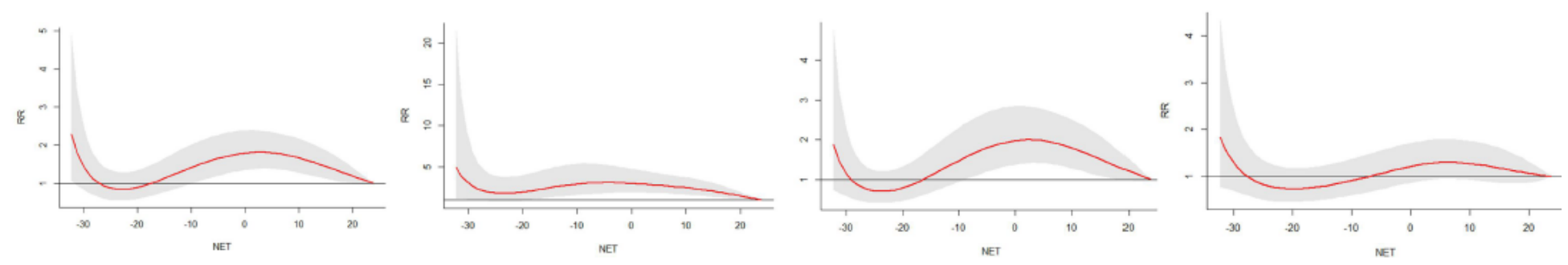

$>3$ years old

Male

Female
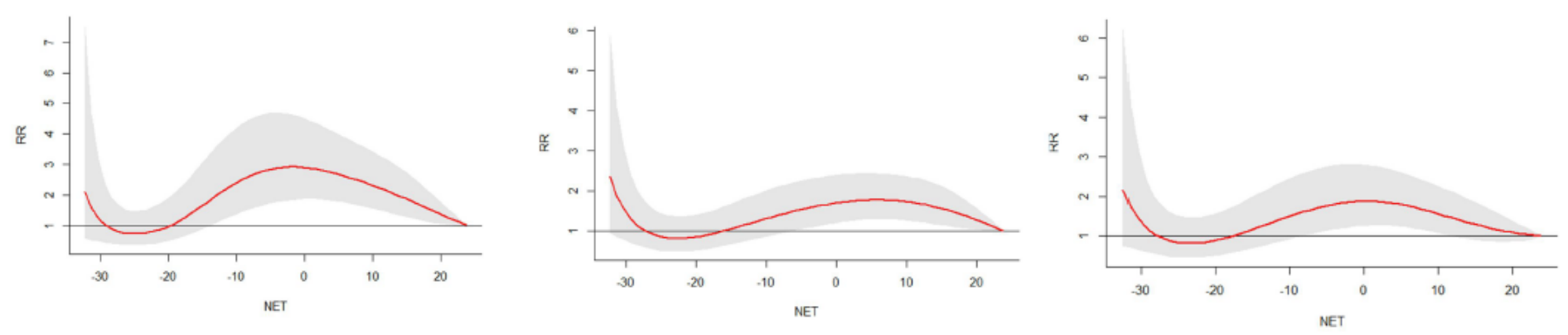

Figure 3

Cumulative effects of NET variables on children's RDHs

\section{Supplementary Files}

This is a list of supplementary files associated with this preprint. Click to download.

- tableS1.xls

- tables4.xls

- tables2.xls

- tables3.xls 